\title{
Mental State Attribution for Interactionism
}

\author{
Uku Tooming \\ Department of Philosophy, University of Tartu
}

\begin{abstract}
Interactionists about folk psychology argue that embodied interactions constitute the primary way we understand one another and thus oppose more standard accounts according to which the understanding is mostly achieved through belief and desire attributions. However, also interactionists need to explain why people sometimes still resort to attitude ascription. In this paper, it is argued that this explanatory demand presents a genuine challenge for interactionism and that a popular proposal which claims that belief and desire attributions are needed to make sense of counternormative behavior is problematic. Instead, the most promising conception of belief and desire ascriptions is the communicative conception which locates them in the context of declarative and imperative communication, respectively. Such a communication can take both verbal and non-verbal form.
\end{abstract}

Keywords: folk psychology, beliefs, desires, communication

\section{Introduction}

Humans are characterized, among other things, by having a particularly complex social life, not only in terms of the quantity of individuals and their interdependence, but also in terms of various abilities which they can rely on in order to cooperate, to compete, and to understand one another. Among these we have the capacity to attribute propositional attitudes, such as beliefs and desires. The development of the capacity to attribute beliefs, which are usually seen as paradigmatic representational mental states, has been especially prominent area of research in developmental psychology and philosophy of mind. Acquiring this ability is often seen as a moment of passing a particularly important developmental hurdle.

Not all agree that propositional attitude attribution is the central element in folk psychology. It has been argued that it is possible to understand

Corresponding author's address: Uku Tooming, Department of Philosophy, Institute of Philosophy and Semiotics, University of Tartu, Ülikooli 18, 50090 Tartu, Estonia. Email: uku.tooming@ut.ee. 
others perfectly well by responding to bodily expressions and by relying on social routines, thus circumventing the need to ascribe beliefs and desires to one another. I use the label 'Interaction Theory' (IT) to denote a plethora of views which claim that propositional attitude attributions are not usually needed in everyday interactions where people anticipate, coordinate with, manipulate, and understand each others' actions. An obvious question to ask is how then the idea of propositional attitudes appeared in the human conceptual repertoire in the first place. If the success in everyday social cognition does not require the ability to ascribe beliefs and desires, what could motivate people to speculate about the complex, contentful inner states that cannot be directly perceived in bodily expressions? There are several answers available.

In this paper, I investigate this question and answers that have been given to it. I will not defend the truth of IT. Instead, I am interested in the conditional question: if IT is true, can it account for the role of propositional attitude attributions? I will proceed as follows. In Section 2, I outline the basic ideas of IT and argue that it is reasonable to bring quite different authors under the same label. Having done that, I go on to analyze different proposals about the role of propositional attitude attributions. In Section 3, I turn to a proposal, endorsed by the main IT theorists and by others, according to which the attribution of propositional attitudes becomes necessary in cases of explaining counternormative or unexpected behavior. I point out certain problems with such an approach, look for a different one in Section 4 and find it from Christopher Gauker's communicative conception which associates belief- and desire-attributions (BD attributions, in short) with the ability to comprehend speech acts. In the end, in Section 5 , I argue that if we extend the basic idea of the communicative conception in a certain way, we can understand why the idea of propositional attitudes could be needed, although humans can mostly get by without it (as IT claims).

\section{Interactionist accounts of social cognition}

The ability to attribute mental states has been one of the main research topics in the interdisciplinary field of social cognition. For a long time, the main theories in that area have been Theory Theory (TT), Simulation Theory (ST) and recently their hybrids. According to TT (Gopnik and Meltzoff 1997; Baron-Cohen 1995), we rely on theoretical information concerning the relations between mental states and behavior when we explain and predict each others' actions. ST, on the other hand, conceives of the process in terms of the attributer imagining herself in the situation of the attributee and projecting the imagined beliefs and desires to her (Goldman 1989; Gordon 1995). Hybrid theories combine elements of the two (Goldman 2006; Stich and 
Nichols 2003). What unifies all three types of theory is the centrality given to mental state attribution (or mentalizing) in social cognition. The paradigmatic mental states have usually been propositional attitudes, such as beliefs and desires. From this point on, I gather these accounts under the label 'Standard Theory-of-Mind,' or simply 'ToM.' The utility of BD attributions is quite apparent in that kind of approach - they provide a primary way to explain and predict behavior.

For some time now, the aforementioned theories have had their dissenters. Shaun Gallagher $(2001 ; 2006)$ has criticized ToM for not doing justice to our experience of people. In a smooth interaction we do not need to speculate about others' unobservable mental states. Instead, responding to the observable bodily expressions and jointly attending to wordly entities suffices to make others intelligible. According to Gallagher, we can directly perceive others' mental states in their expressive behavior (Gallagher 2008a). A number of authors have raised similar criticisms against ToM (De Jaegher and di Paolo 2007; Ratcliffe 2007; Hutto 2004; Leudar et al. 2004). The effectiveness of embodied interactions is also appealed to in order to account for the developmental data, according to which the primary way for infants to make sense of others is constituted by responses to bodily expressions (see Reddy 2008), and this remains operative also in later years (Gallagher 2012, 191).

One might ask whether the critics of ToM are not pursuing a strawman. Also standard ToM theorists are interested in how low-level mindreading works and admit its importance (see Goldman 2006, Ch. 6). What is more, proponents of ToM accept that the ability to attribute mental states builds developmentally upon more embodied ways of responding to one other. For instance, Baron-Cohen (1995) sees the ability to detect intentions and to follow gaze as important precursors of ToM. One must admit, however, that Baron-Cohen construes intention- and gaze-detection mentalistically, in the form of mental state attribution, so that the infant is supposed to produce representations in the form " $\mathrm{x}$ wants this-or-that" and " $\mathrm{x}$ sees this-orthat" (Baron-Cohen 1995, 33). Critics of ToM, on the other hand, construe those abilities which are expressed in embodied interactions as not involving mentalizing. For instance, some enactivists take interaction processes themselves already to constitute social cognition (McGann and de Jaegher 2009; Torrance and Froese 2011), so that guessing the inner causes of others' actions is unnecessary. There are also those who claim that, instead of attributing mental states in everyday interactions, people rely on a skillful know-how which involves a capacity to respond in flexible ways to salient features in the enviroment, in this case the features of the bodily expressions of others. For instance, Hutto understands this kind of responding in terms 
of what he calls "Action Coordination Routines", which do not involve contentful thinking (Hutto 2008, 50). There does seem to exist a genuine antagonism, then, concerning the question of the role of mental state attributions in human social cognition, and the strawman-objection misses its mark. As Gallagher puts it:

IT rejects the supposition of universality in regard to mentalizing, either by theory or by simulation. Rather, mentalizing or mindreading are, at best, specialized abilities that are relatively rarely employed, and they depend on more embodied and situated ways of perceiving and understanding others, which are more primary and pervasive. (Gallagher 2008b, 165)

But what kind of mental states are we talking about when we are talking about mentalizing? When the proponents of IT reject the centrality of attributing or inferring mental states, they do not reject such states that can presumably be observed in the behavior of others without inference, such as emotions or intentions-in-action. What do not seem to be observable are propositional attitudes, such as beliefs and desires, which have a much more tenuous connection to overt behavior. Because of this, the claim that we do not need to attribute or infer mental states should be limited to the attribution or inference of propositional attitudes. My suggestion, then, is that we construe the difference between ToM and IT in terms of their stance on the ability to attribute propositional attitudes: while ToM theorists see it as a pervasively used capacity in social cognition, the proponents of IT deny this and consider it largely unnecessary and dependent on interactive abilities which evolve earlier.

To characterize propositional attitudes, I largely rely on Zawidzki's (2013, 11) account. According to Zawidzki, for a mental state to be a propositional attitude it needs to have semantic properties, thus representing some state of affairs, either actual or possible, under some mode of presentation, and its relation to behavior has to be mediated by a holistic web of other propositional attitudes. The latter aspect is what makes its connection with behavior tenuous-one type of behavior is in accordance with numerous sets of propositional attitudes, which means that the actual set should be inferred somehow, although it cannot be observed. The first feature-propositional attitudes having semantic properties-is basically a conceptual truism. Most importantly, I distinguish between beliefs and desires as forming two main subtypes of propositional attitude, the first representing a state of affairs as 
obtaining, and the second as something to be made to obtain (or something that should obtain). ${ }^{1}$

Given that beliefs and desires present their content in particular ways, there are also specific responses to them, which help us distinguish between the two types of attitude. Beliefs and desires can be understood in terms of what kind of actions they afford to the attributers of these attitudes. In the case of belief, the most immediate reaction is either to agree or disagree with it. More precisely, when a person attributes a belief that $p$ to someone, she can either agree that $p$ is true or disagree. Because to believe that $p$ is is to take $p$ to be true, the most immediate response for an attributer is to evaluate the truth of $p$ oneself. In the case of desire, the respective response is to approve or disapprove it. Since wanting that $p$ involves treating $p$ as something to be pursued or something that should be the case, one can take a stand whether to approve the realization of $p$ or not. Agreement/disagreement and approval/disapproval are the basic content-directed responses to attributed beliefs and desires, respectively. By claiming this, I do not mean that people always respond to attitudes in such ways or that these are the only responses, but these responses reliably indicate that either belief or desire attribution has taken place.

Having distinguished IT and brought out the main characteristics of $\mathrm{BD}$ attribution, one can now ask: how should IT account for the attribution of propositional attitudes? It seems, after all, to be unnecessary for everyday social cognition. The challenge is to explain why one would need the idea of propositional attitudes if one seemingly can get by without it.

It is not entirely clear how to understand this question. One possibility is to apply it to ontogeny, in which case it would be a question about the developmental profile of children: when and why does a child start to apply propositional attitude concepts? Under this interpretation, answering the why-question seems to be easy: she starts to apply those concepts because she has the necessary cognitive mechanisms up and running. One should simply investigate what those mechanisms are and the problem would be solved. My interest here is different, though. The question is, rather: why would anyone need the propositional attitude concepts in the first place? A more promising place to look, then, seems to be the phylogenetic level at which one can ask how our ancestors evolved to the point where applying the concepts of belief and desire payed off to be retained in the conceptual repertoire. That being said, I will rely here on the method of rational reconstruction-the aim is to clarify what benefits the concepts of be-

1 This distinction should map onto the difference in terms of the direction of fit. A gist of this notion was introduced by Anscombe (1959, Sections 2 and 42). For an explicit application of this idea to beliefs and desires, see (Platts 1979). 
lief and desire confer to their possessors which could explain their adoption and maintenance. Such a reconstruction should still cohere with evolutionary and developmental facts and be open to falsification in the light of those facts.

Since I am dealing with a conditional question and assuming that IT is right, I will not go into weighing arguments for and against IT. That being said, I still have to mention and deflate one immediate challenge that arises. For quite some time now, many developmental psychologists and philosophers have argued that infants are able to attribute beliefs earlier than it was usually thought. In their extremely influential paper, Onishi and Baillargeon (2005) used a looking-time measure to show that 15-month-old infants looked longer when an agent searched for an object from a location which was inconsistent with her belief about the location of the object, thus indicating that infants are aware of others having false beliefs. Following studies, often using different methods, indicated that infants may have the ability to attribute beliefs even earlier, going as far as to claim that already 7-month-old infants are able to do it (Kovács et al. 2010). ${ }^{2}$

If the mentalistic interpretation of these studies were correct, it would pose serious problems for IT. If already prelinguistic infants were attributing beliefs (and presumably also desires) to predict and explain behavior, then the idea that attitude attribution is not at the center of our intersubjective engagements would be in jeopardy. IT assumes that our primary way to understand and anticipate each others' actions is non-mentalistic, but the mentalistic interpretation of implicit false belief tasks suggests otherwise.

A promising response to the mentalistic interpretation of infants' abilities, however, is proposed by Cecilia Heyes who argues that instead of endowing infants with the concept of belief we can explain their behavior in implicit false belief tasks in terms of domain-general processes (Heyes 2014). More specifically, she claims that infants' reactions (i.e., longer looking times, anticipatory looking) to agents not acting in accordance with their beliefs are due to low-level novelty of how observable stimuli appear (how colors, shapes and movements are arranged). According to Heyes, we can interpret all the experimental results in terms of low-level perceptual novelty. Naturally, the jury is still out whether all the non-mentalistic re-interpretations by Heyes are fully successful but in the present context it suffices to point out that the results of implicit false belief tasks have not yet demonstrated the need to think that $\mathrm{BD}$ ascriptions are pervasive in human cognition. I will be assuming, then, that IT is a feasible position. ${ }^{3}$

${ }^{2}$ For a general overview of the studies on implicit false belief tasks, see (Carruthers 2013).

3 See also Gallagher's own suggestion of how to interpret implicit false belief tasks nonmentalistically (Gallagher 2012, 197). Both Gallagher's and Heyes's accounts cohere with IT, 
Before moving on, I need to fend off a possible misunderstanding. From the literature on IT one might get the impression that IT is committed to a view that the ability to attribute attitudes is constitutively dependent on language-use. For instance, Hutto is convinced that our ability to understand propositional attitudes (and propositional content more generally) is based on our capacity to comprehend and produce linguistic utterances with sentential content (Hutto 2008, Ch. 5). Hutto's conception of folk psychology as a narrative practice seems to presuppose linguistic determinism and it is supported by another proponent of IT, Shaun Gallagher (Gallagher and Hutto 2008). The defense of this idea coheres well with the non-mentalistic understanding of implicit false belief tasks: if the capacity for BD attributions develops relatively late and builds upon more primary ways of responding, one natural way to conceive of its development is to connect it with language which is also acquired later than the more basic socio-cognitive skills.

However, it is important to keep in mind that IT, as I have defined it, is not committed to linguistic determinism with respect to $\mathrm{BD}$ attributions. It is one thing to claim that $\mathrm{BD}$ attributions constitute a peripheral part of social cognition and it is another thing to say that the capacity to attribute beliefs and desires is constitutively dependent on linguistic capacities. We need not assume the latter. This is a good thing because there is evidence that people with severely impaired grammar still have their mentalizing ability intact (Varley and Siegal 200o; Apperly et al. 2006), suggesting that the linguistic determination thesis is false. This will become important later in this essay.

I can now address a quite popular explanation of why $\mathrm{BD}$ attributions become needed: the Justificatory Role Account.

\section{Propositional attitudes as explanatory devices}

BD attributions help us rationalize behavior (Davidson 1963). To understand why someone acted the way she did, we consider what she wanted to achieve and what she believed was necessary to do in order to satisfy her desires. If some action is puzzling to us, a rationalizing belief-desire explanation can reduce the puzzlement. In recent years, some authors have argued that the need to attribute beliefs and desires arises when one needs to make sense of seemingly irrational or counternormative actions. For instance, Kristin Andrews has argued that an explanation of behavior in terms of attitudes is called for in situations which are anomalous or inappropriate.

but I find the latter more clear. Actually, Gallagher's interpretation may not be so different from Heyes's because he also appeals to the idea that infants' behavior in implicit false belief tasks can be explained in terms of their perceptual expectations (Gallagher 2012, 199). 
Ordinary behavior, on the other hand, can already be explained by appealing to norms (Andrews 2009). This also means that an understanding of norms is developmentally prior to theory of mind. In support of the priorityclaim, Andrews cites evidence from primate studies according to which primates who lack ToM (at least in the sense of the ability to attribute propositional attitudes) have an implicit understanding of norms (Perry et al. 2003; Boesch 2002). She claims that there is a clear benefit that the introduction of reason-explanations confers to a community where people encounter normviolations. Instead of merely punishing the violator, one can ask for the reason why she acted in this way and try to justify it; justification can then help to refine norms and develop new ones (Andrews 2009, 445).

Another author who has proposed a similar idea is Tad Zawidzki. To understand his proposal, one should take into account his general approach to understanding human cognition. According to Zawidzki, our speciesspecific cognitive endowments are largely a result of mindshaping mechanisms which have molded our minds and behaviors to be (relatively) predictable and homogenous. These mechanisms underlie such processes as imitation, natural pedagogy, submission to norms and language-based regulative frameworks (Zawidzki 2013, 29). Because mindshaping regulates human behavior, there is usually no need to attribute beliefs and desires in order to know what a person will do or to understand why she acted in the way she did. The question arises, then, what are the conditions, given the overall homogeneity of human behavior and thought, for attributing propositional attitudes.

Zawidzki grounds the capacity to attribute propositional attitudes in the practice of undertaking and attributing discursive commitments. The idea of conceptualizing linguistic practice in such a way goes back to Brandom (2000). Zawidzki takes over the basic idea and argues that the ability to undertake and attribute such commitments is a result of language-based regulation of behavior (a form of mindshaping), most notably expressed in the practices of promising and asserting (Zawidzki 2013, 216). If a person promises or asserts something, she commits herself to future courses of action. For instance, in case of assertion, the asserter commits herself to justify her assertion when challenged. Violations of such commitments provoke sanctions and bring about a loss of social prestige and status. Zawidzki argues that the need for $\mathrm{BD}$ attributions arises in situations wherein a person persists in violating her discursive commitments, which then calls for the question: what does she really think (Zawidzki 2013, 218)? The answer to this question, if acceptable, may rehabilitate her social status and explain her counternormative behavior. For Zawidzki, then, the primary role of attitude ascriptions is justificatory. 
Such an approach to BD attributions is also endorsed by the main proponents of IT like Dan Hutto and Shaun Gallagher. Hutto's Narrative Practice Hypothesis (NPH) assumes that belief and desire attributions earn their keep in explaining norm-violating behaviors (Hutto 2008, 7; Gallagher agrees with this, see Gallagher and Hutto 2008). Framing such behaviors in terms of a narrative which makes reference to agents' beliefs and desires helps us understand why they acted that way. Hutto admits that sometimes when a behavior is especially strange, a reference to beliefs and desires is insufficient, and then a more informative narrative is needed. Nevertheless, the attribution of beliefs and desires still functions in the context of making sense of behaviors which violate some norm. It thus has a relatively limited but still important role to play in social cognition.

Although Andrews, Zawidzki and Hutto approach the issue of propositional attitude attributions from different angles, the content of their proposals is very similar. All of them take the justification of norm-violating behavior to be the main role of $\mathrm{BD}$ attributions. Let's call this view 'Justificatory Role Account' (JRA). In what follows, I raise some concerns about JRA. It is important to note that Andrews and Zawidzki do not take themselves to be interactionists. However, their explanations of $\mathrm{BD}$ attribution can be nicely located within the IT framework.

So what are the difficulties that JRA faces? The first, least serious problem is that attitude ascriptions are also perfectly appropriate when we explain behaviors which do not violate any norms. If someone goes to a store and buys milk, we can explain her action by citing her desire to drink milk and her belief that the store sells it. This is a perfectly understandable context wherein no norm is violated. The fact that $\mathrm{BD}$ explanations are rationalizing explanations thus does not mean that they are always meant to justify norm violations. One can object, however, that this should not be really damaging to JRA because the idea is rather that people are motivated to ascribe beliefs and desires to rehabilitate normative status. Behaviors which do not violate norms are supposedly also understandable without ascribing these attitudes.

The problem with this response is that the present question is not when people are motivated to attribute beliefs and desires, given that the respective contexts are already in use, but the question is: what could be the motivation for introducing the concepts of belief and desire in the first place? The fact that people have a tendency to ascribe attitudes when the normative status of the attributee is in jeopardy does not entail that that is the primary rationale for doing this. However, even if we accept that JRA is correct in claiming that counternormative contexts are significantly different from those that are not, JRA faces a more serious problem. This concerns the fact that there are other ways of offering normalizing explanations than by appealing to 
$\mathrm{BD}$ attributions and which are presumably more simple, circumventing the need to ascribe attitudes. For instance, the explanatory role of norms could also be extended to behaviors which do not accord with a particular norm. This idea might sound paradoxical but it is not. Consider the possibility that different norms can apply to the same action-type. Although an action may violate one norm, it can still accord with a different one. An appeal to that second norm can then indicate why the action was reasonable without one having to make any reference to beliefs and desires of the agent. Take, for instance, Andrews's example of a colleague yelling obscenities to a girl on the street (Andrews 2009, 437). This is a situation which violates a norm of politeness wherein one obvious way to make sense of the colleague's behavior is to ask what he believes about the girl. An explanation in terms of an alternative norm, however, can work just as well. One only needs to introduce a norm which specifies conditions under which it would be allowed to yell obscenities to another person and to explain the action by stating that these conditions are met. Note that this does not require buying into such a norm oneself, nor does it imply that the norm which is used in the explanation is a good one. What is important is that by specifying the new norm one does not have to speculate about the contentful mental states of the rude person; there is no need for $\mathrm{BD}$ attributions. The alternative explanation is simpler because the understanding of norms is something that already exists in the community, while the concepts of belief and desire have not yet been introduced.

One can object that there are situations wherein such a normalization of behavior does not seem to work. This becomes apparent when we consider violations of discursive commitments in which case there is less room for thinking about alternative norms that would justify behavior. Yelling obscenities is presumably not an example of full-fledged discursive action. Let's take Zawidzki's example of a hunter who reports the location of prey to be in the north, and when it turns out that there is no prey to the north he can justify his assertion by appealing to his belief that there was prey to the north (Zawidzki 2013, 220). Because the minimal norm for (sincere) assertion is that it should be true (Turri 2013), a justification of the assertion by an alternative norm is suspect. Possible alternative norms, like knowledge or belief, make reference to propositional attitudes and are thus of no use in the present context.

One should note, however, that this adds a serious qualification to JRA by limiting the cases when $\mathrm{BD}$ attributions are needed. What is even more problematic is that this concession seems to commit one to accept linguistic determinism about $\mathrm{BD}$ attributions which I rejected in the previous section. In addition, I am not sure whether the appeal to the peculiarity of discursive 
commitments is successful. It still excludes alternative ways to justify normviolating behaviors. For instance, the hunter could also justify his mistaken assertion by claiming that his evidence was indicating that prey was to the north. Evidence need not make any reference to the hunter's propositional attitudes. In response, one could argue, by appealing to mentalism in epistemology, that evidence for a proposition consists in having certain mental states (Conee and Feldman 2001). In such a case, an appeal to subjective evidence would involve attributing beliefs (or seemings) to oneself. But at the moment we are considering a community where the concepts of belief and desire are lacking and it seems strange to claim that people in such a community cannot have any understanding of evidence. We can think of such evidence (or quasi-evidence, if you want) in factual terms, so that the hunter's appeal to evidence would mean that there are certain signs to the north that usually indicate the presence of the prey.

There are additional problems with JRA. There is a type of action-explanation that has been completely overlooked by the proponents of JRA, namely, the explanation of actions in terms of other actions. An example would be an action of breaking eggs in a process of making an omelet. The action of making an omelet explains why the person is breaking eggs. Actions are embedded in other actions and explanations can take advantage of that fact, without necessarily referring to mental states. Michael Thompson calls these "naive explanations of action" and argues that they constitute the most fundamental form that action explanations take (Thompson 2008). For the present purposes, it is important to point out that such explanations are feasible alternatives to explanations in terms of attitudes. Naive action explanations can also function as normalizing explanations: by locating a strange action within the structure of an acceptable one we can make the first intelligible in terms of the second. This circumvents the need to attribute attitudes. Again, as in the case of alternative norms, naive action explanations seem to be simpler than explanations in terms of BD attributions. If a community lacks the attitude concepts, it is more natural to apply the already existing knowledge about the teleologial structure of action than to introduce new concepts.

One could raise the concern that perhaps the reference to attitudes in the case of action-based explanations is simply unmarked while there is still an implicit reference (for the markedness-unmarkedness distinction, see Malle et al. 2007). If this were true, the explanations in terms of actions would not constitute an alternative to explanations in terms of attitudes. ${ }^{4}$ I would point out, however, that Thompson's arguments are meant to show that naive explanations are irreducible to the more sophisticated ones and it is a burden

${ }^{4}$ I thank an anonymous reviewer for pressing me on this issue. 
on the opponent to prove that they still implicitly involve $\mathrm{BD}$ attributions. More importantly, there are empirical reasons to think that naive actionexplanations are not mentalistic in nature. Already six-and-a-half month old infants who presumably lack the capacity to mindread are able to understand goal-directed actions, indicating that the ability to grasp the teleological structure of actions is irreducible to explanations in terms of $\mathrm{BD}$ attributions (Csibra 2008; see also Gergely and Csibra 2003).

As for another objection, it is not completely clear whether a naive action explanation can be applied to expressions of discursive commitments as brought out in Zawidzki's example. What is the wider action that justifies the hunter's false assertion but which does not make reference to beliefs and desires? Well, he might say that he asserted that prey was to the north because he was informing others about the prey's location, given the evidence he had. Admittedly, in such a case the justificatory burden seems to be carried by his evidence, not his action. This would bring us back to the question of whether evidence has to involve reference to beliefs and desires and I already argued that we should not assume that. ${ }^{5}$

We can say, then, that the justification of behavior is not solely the province of $\mathrm{BD}$ attributions. It can be accomplished by other, more minimalist means which rely on resources which are already available for a community whose members do not yet possess the concepts of belief and desire: understanding of norms and of the structure of actions. This does not entail a definite falsity of JRA, of course. Nonetheless, it reduces motivation for it. Since we are interested in the question of why the attitude attributions were introduced in the first place, it is not clear whether such attributions are needed if they do not deliver a distinctive benefit. JRA thus faces various challenges. In what follows, I will propose that Christopher Gauker's communicative conception of beliefs and desires is a more promising way for IT to explain the need for the concepts of belief and desire.

\section{The communicative conception and IT}

In Section 2, I claimed that BD attributions are indicated by the responses of agreement/disagreement and approval/disapproval. These are proper responses not only to beliefs and desires, however. We can also agree with what others have asserted and we can approve others' commands. The responses in question find their home in the communicative behavior of human beings and are most apparent in communicative contexts.

5 As I pointed out earlier, limiting BD attributions to discursive contexts also seems to entail a problematic form of linguistic determinism. 
It could be argued that the appropriateness of these responses to assertions and commands derives from the underlying attitudes, so that when we agree or disagree with an assertion we are actually agreeing or disagreeing with the belief that this assertion expresses, and when we approve or disapprove a command we are actually approving or disapproving the desire that is expressed by the command. This is not the only way to see the relation between attitudes and speech acts, however. Christopher Gauker's communicative conception of beliefs and desires (henceforth, CC) provides an alternative. According to Gauker, if we attribute a belief to someone, we are actually making an assertion on her behalf; and if we attribute a desire, we are making a command on her behalf (Gauker 2003, 221). CC understands beliefs and desires in terms of the respective speech acts, not the other way around. The attribution of attitudes is conceived of as an extension of the practice of linguistic communication. For example, if $X$ asserts that there is a new Chinese restaurant in town, Y can convey X's assertion by saying that $\mathrm{X}$ believes that there is a new Chinese restaurant in town; and if $\mathrm{X}$ orders $\mathrm{Y}$ to do the dishes, $\mathrm{Y}$ can say that $\mathrm{X}$ wants her to do the dishes. The content of the ascribed attitude does not have to fully match the content of the respective speech act that is being conveyed and it is also possible to assert or command on X's behalf (i.e., attribute a belief or a desire) without $\mathrm{X}$ having performed the respective speech act. Mental state attributions thus transcend the actual linguistic behavior of the attributee, but are still identifiable as language-involving acts. It is important to point out that the assertions and requests can also be performed silently, without uttering them aloud.

It should be easy to see that CC provides an answer to the question of this essay, namely: why do we need to introduce the concepts of belief and desire if they generally do not play a central role in our everyday interactions (i.e., assuming the truth of IT)? According to CC, the concepts of belief and desire find their use in extending the practice of linguistic communication: they enable us to assert and command on others' behalf. A proponent of IT can thus accommodate this explanation into her overall theory. The use for $\mathrm{BD}$ attributions will be confined to certain contexts and does not pervade our typical interactions in which we dispense with the need for BD attributions and rely on embodied interaction and normative frameworks instead. ${ }^{6}$ Keep in mind that Gauker himself is not an interactionist, but IT can use his conception of $\mathrm{BD}$ attributions, given that $\mathrm{CC}$ and IT share the view about the extent to which people engage in $\mathrm{BD}$ attributions. It seems to fit into the general framework in which three levels of intersubjectivity are distinguished, so that $\mathrm{BD}$ attributions become necessary only at the third level which in-

${ }^{6}$ I should note in advance that I eventually reject CC in its original form. 
volves linguistic skills (Gallagher and Hutto 2008). ${ }^{7}$ Although Gallagher and Hutto associated the capacity to ascribe attitudes most closely with the participation in narrative practices, the grasp of imperative and assertive speech acts is also something that belongs to the third level of intersubjectivity.

But why exactly does one have to introduce new concepts to assert and command on others' behalf? Are not the concepts of assertion and command enough? Gauker suggests that the attribution of an attitude, instead of restating the respective speech act, is useful when the authority or reliability of the person who uttered the speech act is in doubt (Van Cleave and Gauker 2010, 310). The attitude concepts are used when the vicarious speech acts are qualified in important respects. This difference between speech acts and attitudes seems to be relatively superficial, however. To understand a more important difference, it is important to repeat that $\mathrm{BD}$ attributions do not have to track the actual assertions and commands of attributees: sometimes it is appropriate to assert or command on a person's behalf even when he or she has not performed the respective speech act. Nevertheless, by attributing the respective attitude we can treat her as if she had asserted or commanded. For instance, if a person's behavior indicates that it is rational for her to assert that $p$, we can treat her as if she had asserted it by attributing to her the belief (i.e., by asserting on her behalf) that $p$, so that it would be possible to express one's disagreement with her. A good example of such a context is the case of attributing an implicit belief that $p$ : although the person is not disposed to assert that $p$, her behavior is in accordance with such an assertion. ${ }^{8}$ For instance, if one asserts that all races are equal but tends to act in discriminatory ways toward people of other color, we can assert on her behalf (i.e., attribute a belief to her) that all races are not equal (see Schwitzgebel 2010, 532). In the case of desire attributions, on the other hand, the facts about what a person is disposed to like and take pleasure in constitute the best indicator of what it is appropriate to command on her behalf (see Tooming 2014). For example, if one knows that another person is hungry and would enjoy eating some cake, one can request a piece of cake on her behalf (given that one has other-regarding motivation) and attribute a desire for a piece of cake by doing it.

One can be motivated to make such vicarious utterances while not intending to respect the dispositional facts about another person. The con-

7 The first level involves embodied practices like imitation, perception of intentions and responses to expressions of emotion (Gallagher and Hutto 2008, 20) and the second consists in understanding others' actions in pragmatic contexts (Gallagher and Hutto 2008, 23).

8 The behavior which is in accordance with the assertion that $p$ should be specifiable without any reference to propositional attitudes, otherwise the explanation of the concept of belief would be circular. For a proposal how to do this, see (Stout 2006, 123). 
cerns about appropriateness come into play when the attributer has the epistemic interest in accurately capturing the dispositions of the attributee. There are many cases, however, when the assertion or request on another person's behalf is meant to damage or improve her social status. For instance, if we treat someone as if she had asserted something ridiculous (i.e., take them to believe something ridiculous), we can bring into question her trustworthiness. The practice of speaking for others is loaded with political motives and often functions to perpetuate unequal relations between people (Alcoff 1991). ${ }^{9}$ Instead of understanding the motivation to introduce attitude concept in narrowly epistemic terms we should treat the usefulness of BD attributions in a broader sense, involving both epistemic and pragmatic motivation to treat others as if they had asserted or requested something. We can then articulate more broadly what the introduction of the concepts of belief and desire adds to the socio-cognitive practice: the concept of belief is used to assert on X's behalf when X has not made the respective assertion, but it is useful-where usefulness is understood in the broad sense-to treat her as if she did; and the concept of desire is used to command on X's behalf when $\mathrm{X}$ herself has not made the respective command, but it is useful to treat her as if she did. The important point is that there is plenty of motivation to introduce $\mathrm{BD}$ attributions as assertions and requests on others' behalf to the communicative practice.

The communicative conception is in a good position to make explicit why the responses of agreement/disagreement and approval/disapproval are characteristic reactions to attributed beliefs and desires, respectively: they derive from our practice of making assertions and commands. More importantly, while JRA faced the difficulty with excluding alternative, more simple ways of normalizing behavior (alternative norms and other actions), $\mathrm{CC}$ demonstrates a need for $\mathrm{BD}$ attributions which presumably cannot be satisfied by other means. It is difficult to find any other way in which one could treat another as if the latter had asserted or commanded something than by attributing beliefs and desires to her, and my bet is that there really is not any other way. Finally, CC is also able to explain how BD attributions can be employed to explain behavior, be it counternormative or not. $\mathrm{CC}$ achieves this by reconstructing $\mathrm{BD}$ explanations as attributions of inner conversations. If we are rationalizing someone's behavior in terms of beliefs and desires, we are requesting on her behalf that she achieve a certain goal and we are asserting on her behalf how to achieve it (Gauker 1994, 277).

9 CC can thus take on board Zawidzki's idea that attitude attributions play an important role in impression management (Zawidzki 2013, 224). Unlike Zawidzki, though, I do not locate the need to introduce the concepts of belief and desire in an explanatory context and I take $\mathrm{BD}$ attributions to often have damaging effects on the attributee. 
Gauker has also applied CC to explain the acquisition of the concepts of belief and desire. In (Van Cleave and Gauker 2010) it is argued that explicit false-belief tasks (passing of which has been often taken as an indicator of a child's having the concept of belief) invite a child to consider what a person's contribution to the conversation would be. So for instance, if a child is asked what a person thinks a Smarties box contains, she should respond that the person in question thinks that the box contains Smarties (not pencils, which the box actually contains), and by doing that she simply asserts on that person's behalf what her contribution to the conversation about the contents of the box would be (Van Cleave and Gauker 2010, 316). CC also explains developmental data quite well. For instance, children seem to master the concept of desire earlier than the concept of belief (Wellman and Woolley 1990). The communication conception offers an explanation. According to Van Cleave and Gauker, this is due to the fact that children are able to understand and produce commands before they master the belief-talk (Van Cleave and Gauker 2010, 318). Such a developmental asymmetry between two kinds of speech act understanding has empirical support (Rakoczy and Tomasello 2009).

The communicative conception, then, seems to provide a suitable explanation of why the concepts of belief and desire would be needed in our everyday communicative practices, assuming that IT is on the right track. However, CC faces one serious difficulty. It seems to be committed to linguistic determinism, i.e., the idea that $\mathrm{BD}$ attributions are constitutively dependent on linguistic abilities. Gauker is quite explicit about the tight connection between the two, claiming that the mentalizing ability only develops together with linguistic competence (Gauker 2011, 167). There is evidence, however, already pointed out in Section 2, which suggests that the ability to ascribe attitudes can be present while a person has seriously impaired language ability. ${ }^{10}$ This indicates that by assuming linguistic determinism as CC does, IT is vulnerable to the existing evidence against determinism. We should look whether the insights expressed by CC could be extended so that it would avoid this vulnerability. In the next section, I am going to offer a suggestion for how to do that.

\section{Beliefs and desires in gestures}

According to the communicative conception, by attributing beliefs and desires to others we can treat them as our communication partners who we can

${ }^{10}$ To be fair to Gauker, he acknowledges the data in question but dismisses it too quickly by speculating that perhaps agrammatic aphasics have retained the ability that they acquired when they still had their linguistic abilities (Gauker 2011, 170). This speculation seems quite ad hoc. 
evaluate through agreement/disagreement and approval/disapproval, even when explicit communication is absent. If we accept CC in its present form, $\mathrm{BD}$ attributions are limited to contexts of linguistic communication. Not all communication involves language, however. People also express themselves emotionally, engage in joint attention and use pointing to get what they want from each other. In what follows, I intend to argue that CC and IT do not have to be committed to the idea that the understanding of attitudes requires linguistic capacities. The relevant responses can also arise in non-linguistic contexts and, as it turns out, we can find these responses already at the level of gestural communication.

A fundamental type of gesture which belongs to the basic level of human intersubjectivity is pointing. By pointing to objects in the environment, people can guide each others' attention and establish social relations. It is also one of the earliest forms of gesture that infants learn. Pointing to objects and events may serve different purposes, however. It can be used to indicate something in the environment out of curiosity or in order to indicate a possible threat, but it can also be employed to order someone to bring the object which is being pointed at. A distinction in that regard has been drawn between declarative and imperative pointing. Imperative pointing is presumably instrumental, in that the one who points uses another person as a means to get the object that is pointed at, while declarative pointing is used to share attention with another person (Tomasello 1999). Besides declarative pointing, we can also talk about informative pointing, the aim of which is not simply to share attention, but to share information (Liszkowski et al. 2006), or interrogative pointing, the aim of which is to get information about the object or event pointed at (Southgate et al. 2007).

For the present purposes, the general distinction between imperative and declarative pointing suffices, so that the latter also covers informative and interrogative gestures, as long as this allows us to differentiate between two kinds of response profile with regard to two general types of pointing. These two kinds map onto the responses of approval/disapproval and agreement/disagreement, respectively. If such responses were also appropriate with respect to pointing gestures, there would be room to argue that $\mathrm{BD}$ attributions could already be involved at the level of pointing.

In the case of imperative pointing, it is easy to see that something like approval or disapproval is the appropriate evaluative response to it: if a person, $\mathrm{A}$, points to an object, $\mathrm{X}$, so that another person, $\mathrm{B}$, would bring $\mathrm{X}$ to her, then $\mathrm{B}$ can choose whether to follow the imperative or not, thus expressing his approval or disapproval of A's act. We can say that imperative pointing has the same (or at least similar) communicative significance as commanding: both call for a specific type of response which consists in the evaluation 
of whether what is gestured at and commanded should be received by A or not. Imperative pointing is a primitive type of command.

When we turn to the acts of declarative pointing, it is not so clear that agreement or disagreement are proper responses to them. By declaratively pointing to $\mathrm{X}$, a person does not seem to make a claim about $\mathrm{X}$ which another person can then agree or disagree with. To arrive at these responses we need to introduce more communicative context. Declarative pointing can often be motivated by a question. Imagine a situation where A seeks for X, while B watches. If A declaratively points to a location, $\mathrm{B}$ can then agree or disagree in response to that gesture as to whether $\mathrm{X}$ is actually in that location. There is also an additional way in which a declarative gesture can be assertionlike: if A points toward a specific location and mimics the appearance of $X$, he can convey a claim that $\mathrm{X}$ is in that location (see Sterenly 2012, 2145). B who sees this act can then evaluate whether the conveyed claim is true or not. These examples should suffice to show that declarative pointing can motivate agreement or disagreement, just like assertions (or beliefs) do.

The responses of agreement/disagreement and approval/disapproval, then, are not only apparent in the context of linguistic communication, but they come up in gestural communication as well. This fact lets us locate the need for the concepts of belief and desire already at the level of pointing. The concept of belief can already be introduced in order to enable one to react to another person as if she had performed an act of declarative pointing. As we can treat someone as if she had asserted something, given her behavioral dispositions, so we can treat her in certain contexts as if she had declaratively pointed to something, and this can constitute a belief attribution. The concept of desire, on the other hand, can be used to treat another person as if she had pointed imperatively, again given her behavior and reactions. $\mathrm{BD}$ attributions, then, can be taken to be a form of pointing on others' behalf, or simulated pointing. ${ }^{11}$ As in the case of assertions and commands, the practice of attributing beliefs and desires extends the responses of agreement/disagreement and approval/disapproval to situations wherein an agent has not explicitly pointed (or perhaps her authority is under doubt), but when it is still proper to treat her as if she had. According to such a modified version of CC, mental state attribution is not explained by speech act understanding. There is an explanatorily more basic level at which the characteristic responses to attitudes are exhibited-the level of gestural communication.

This proposal coheres well with IT because it takes $\mathrm{BD}$ attributions to be a relatively rare, but still an important part of human social cognition, which

${ }^{11}$ It is important to stress that pointing on another's behalf does not have to involve a physical act of pointing. Instead, mental simulation suffices. 
is employed in communicative contexts. It is not committed to the idea that beliefs and desires are posits which are necessary for explaining and predicting behavior or for engaging in everyday social interactions, and it does not presuppose linguistic determinism of BD attributions either. Admittedly, this is also a speculative proposal. Nevertheless, it coheres with the developmental data, according to which the capacity to point declaratively emerges later than imperative pointing (Camaioni et al. 2004). Since there is a similar developmental asymmetry also between belief- and desire-attributions, it is reasonable to speculate that the asymmetries between the development of two types of attitude attribution and between declarative and imperative pointing are intimately connected. Naturally, this connection needs to be submitted to further empirical scrutiny.

In any case, IT which adopts such an extension of CC should accept that the capacity for BD attribution is probably acquired earlier than the results of the explicit-false belief tasks seem to suggest (this is something that Gauker himself would deny). This also means that, pace Gallagher and Hutto (2008), BD attributions should be located at the second level of intersubjectivity which develops ontogenetically before the mastery of linguistic practices and involves understanding the pragmatic contexts of others' actions (Gallagher and Hutto 2008, 23). The fact that pointing on others' behalf already involves $\mathrm{BD}$ attributions gives a reason to think that the respective capacity emerges quite early in development. A suitable type of experiment by which to test this might already be available, namely, the active-helping paradigm in which a child is invited to help another person to find an object by pointing to the right location. This requires understanding to what location it is proper to point, given the seeking behavior of another person. Evidence indicates that children pass this test already by the 18-month mark (Buttelman et al. 2009). ${ }^{12}$ Some interactionists might balk at the suggestion that such tasks demonstrate genuine understanding of belief but if we take IT to be primarily a position about the extent to which people resort to mentalizing, we should accept the mentalizing interpretation of the data from the active helping paradigm. In Section 2, I already argued that IT, as I define it, need not assume that the development of $\mathrm{BD}$ attribution is constitutively dependent on linguistic abilities.

One should also keep in mind that accepting the mentalizing interpretation of the active helping paradigm does not commit us to understand other implicit false belief tasks in terms of $\mathrm{BD}$ attributions. Given that the present view locates $\mathrm{BD}$ attributions in a communicative context, observational paradigms for testing the capacity to attribute false beliefs, such as violation of expectation and anticipatory looking, are given lower-level ex-

${ }^{12}$ Admittedly, the study only investigated belief attribution. 
planations in terms of perceptual novelty, à la Heyes. We need not give the same interpretation to different paradigms that have been intended to probe mentalizing capacities in young infants. According to the present picture, active helping requires an exercise of different capacities than the observational paradigms do. The latter do not reveal a primary way of responding to one another. The need for BD attributions is still limited to specific communicative contexts (pace ToM).

\section{Conclusion}

In this paper I argued that if Interaction Theory is to explain the role of belief and desire attribution in human social life, it has to locate it in the context of interpersonal communication, both verbal and nonverbal. A popular proposal which takes them to be devices for normalizing explanation does not account for the primary significance of these attributions. If one believes that Interaction Theory is on the right track and attitude ascriptions are a relatively peripheral part of social cognition, the Communicative Conception is the most promising account of these attributions, as long as one keeps in mind that beliefs and desires are not only attributed to assert or command, but also to point on others' behalf.

\section{Acknowledgments}

Research in this paper was supported by the Estonian Science Foundation grant ETF9117, the Centre of Excellence in Estonian Studies (European Union, European Regional Development Fund) and is related to research project IUT20-5 (Estonian Ministry of Education and Research). Thanks to Riin Kõiv and Taavi Laanpere for helpful discussion and to conference participants in Bochum (June 2014) who gave feedback to an earlier version of this paper.

\section{Bibliography}

Alcoff, L. (1991). The problem of speaking for others, Cultural Critique 20: 532.

Andrews, K. (2009). Understanding norms without a theory of mind, Inquiry 52: 433-448.

Anscombe, E. (1959). Intention, Blackwell, Oxford. 
Apperly, I., Samson, D., Carroll, N., Hussain, S. and Humphries, G. (2006). Intact first- and second-order false belief reasoning in a patient with severely impaired grammar, Social Neuroscience 1: 334-348.

Baron-Cohen, S. (1995). Mindblindness: An Essay on Autism and Theory of Mind, MIT Press, Cambridge, MA.

Boesch, C. (2002). Cooperative hunting roles among taïe chimpanzees, $\mathrm{Hu}$ man Nature 13: 27-46.

Brandom, R. (2000). Articulating Reasons: An Introduction to Inferentialism, Harvard University Press, Cambridge, MA.

Buttelman, F., Carpenter, M. and M., T. (2009). Eighteen-month-old infants show false belief understanding in an active helping paradigm, Cognition 112: $337-342$.

Camaioni, L., Perucchini, P., Bellagamba, F. and Colonnesi, C. (2004). The role of declarative pointing in developing a theory of mind, Infancy 5: 291308.

Carruthers, P. (2013). Mindreading in infancy, Mind and Language 28: 141172.

Conee, E. and Feldman, R. (2001). Internalism defended, American Philosophical Quarterly 38: 1-18.

Csibra, G. (2008). Goal attribution to inanimate agents by 6.5-month-old infants, Cognition 107: 705-717.

Davidson, D. (1963). Actions, reasons, and causes, The Journal of Philosophy 63: 685-700.

De Jaegher, H. and di Paolo, E. (2007). Participatory sense-making: An enactive approach to social cognition, Phenomenology and the Cognitive Sciences 6: 485-507.

Gallagher, S. (2001). The practice of mind: Theory, simulation, or interaction, Journal of Consciousness Studies 8: 83-107.

Gallagher, S. (2006). How the Body Shapes the Mind, Clarendon Press, Oxford.

Gallagher, S. (2008a). Direct perception in the interactive context, Consciousness and Cognition 17: 535-543.

Gallagher, S. (2008b). Inference or interaction? Social cognition without precursors, Philosophical Explorations 11: 163-174.

Gallagher, S. (2012). In defence of phenomenological approaches to social cognition: Interacting with the critics, Review of Philosophy and Psychology 3: 187-212. 
Gallagher, S. and Hutto, D. (2008). Understanding others through primary interaction and narrative practice, in J. Zlatev, T. Racine, C. Sinha and E. Itkonen (eds), The Shared Mind: Perspectives on Intersubjectivity, John Benjamins, Amsterdam, pp. 17-38.

Gauker, C. (1994). Thinking Out Loud: An Essay on the Relation between Thought and Language, Princeton University Press, Princeton.

Gauker, C. (2003). Words without Meaning, MIT Press, Cambridge, MA.

Gauker, C. (2011). Words and Images: An Essay on the Origin of Ideas, Oxford University Press, New York.

Gergely, G. and Csibra, G. (2003). Teleological reasoning in infancy: The naive theory of rational action, Trends in Cognitive Sciences 7: 287-292.

Goldman, A. (1989). Interpretation psychologized, Mind \& Language 4: 161185.

Goldman, A. (2006). Simulating Minds: The Philosophy, Psychology, and Neuroscience of Mindreading, Oxford University Press, New York.

Gopnik, A. and Meltzoff, A. (1997). Words, Thoughts, and Theories, MIT Press, Cambridge, MA.

Gordon, R. (1995). The simulation theory: Objections and misconceptions, Mind \& Language 7: 1-10.

Heyes, C. (2014). False belief in infancy: A fresh look, Developmental Science 17: $647-659$.

Hutto, D. (2004). The limits of spectatorial folk psychology, Mind \& Language 19: 548-573.

Hutto, D. (2008). Folk Psychological Narratives: The Sociocultural Basis of Understanding Reasons, The MIT Press, Cambridge, MA.

Kovács, Á., Téglás, E. and Endress, A. (2010). The social sense: Susceptibility to others' beliefs in human infants and adults, Science 330: 1830-1834.

Leudar, I., Costall, A. and Francis, D. (2004). Theory of mind: A critical assessment, Theory \& Psychology 14: 571-578.

Liszkowski, U., Carpenter, M., Striano, T. and Tomasello, M. (2006). 12- and 18-month olds point to provide information for others, Journal of Cognition and Development 7: 173-187.

Malle, B. F., Knobe, J. and Nelson, S. (2007). Actor-observer asymmetries in behavior explanations: New answers to an old question, Journal of Personality and Social Psychology 93: 491-514.

McGann, M. and de Jaegher, H. (2009). Self-other contingencies: Enacting social perception, Phenomenology and the Cognitive Sciences 8: 417-437. 
Onishi, K. and Baillargeon, R. (2005). Do 15-month-old infants understand false beliefs, Science 308: 255-258.

Perry, S., Baker, M., Fedigan, L., Gros-Louis, J., Jack, K., MacKinnon, K., Manson, J. H., Panger, M., Pyle, K. and Rose, L. (2003). Social conventions in wild white-faced capuchin monkeys, Current Anthropology 44: 241258.

Platts, M. (1979). Ways of Meaning, Routledge and Kegan Paul, London.

Rakoczy, H. and Tomasello, M. (2009). Done wrong or said wrong? Young children understand the normative directions of fit of different speech acts, Cognition 113: 205-212.

Ratcliffe, M. (2007). Rethinking Commonsense Psychology: A Critique of Folk Psychology, Theory of Mind and Simulation, Palgrave MacMillan, New York.

Reddy, V. (2008). How Infants Know Minds, Harvard University Press, Cambridge, MA.

Schwitzgebel, E. (2010). Acting contrary to our professed beliefs or the gulf between occurrent judgment and dispositional belief, Pacific Philosophical Quarterly 91: 531-553.

Southgate, V., van Maanen, C. and Csibra, G. (2007). Infant pointing: Communication to cooperate or communication to learn?, Child Development 78: 735-740.

Sterenly, K. (2012). Language, gesture, skill: The co-evolutionary foundations of language, Philosophical Transactions of the Royal Society $B$ 367: 2141-2151.

Stich, S. and Nichols, S. (2003). Mindreading: An Integrated Account of Pretence, Self-Awareness, Understanding Other Minds, Oxford University Press, New York.

Stout, R. (2006). The Inner Life of a Rational Agent. In Defense of Philosophical behaviorism, Edinburgh University Press, Edinburgh.

Thompson, M. (2008). Life and Action. Elementary Strutures of Practical Thought, Harvard University Press, Cambridge, MA.

Tomasello, M. (1999). The Cultural Origins of Cognition, Harvard University Press, Cambridge, MA.

Tooming, U. (2014). Pleasures of the communicative conception, Grazer Philosophische Studien 90: 253-272. 
Torrance, S. and Froese, T. (2011). An inter-enactive approach to agency: Participatory sense-making, dynamics, and sociality, Humana.Mente 15: 21-53.

Turri, J. (2013). The test of truth: An experimental investigation of the norm of assertion, Cognition 129: 279-291.

Van Cleave, M. and Gauker, C. (2010). Linguistic practice and false-belief tasks, Mind \& Language 25: 298-328.

Varley, R. and Siegal, M. (2000). Evidence for cognition without grammar from causal reasoning and "theory of mind" in an agrammatic aphasic patient, Current Biology 10: 723-726.

Wellman, H. and Woolley, J. (1990). From simple desires to ordinary beliefs: The early development of everyday psychology, Cognition 35: 245-275.

Zawidzki, T. (2013). Mindshaping: A New Framework for Understanding Human Social Cognition, MIT Press, Cambridge, MA. 